\title{
Thresholds for the perception of angular acceleration as indicated by the oculogyral illusion
}

\author{
EARL F. MILLER II and A. GRAYBIEL \\ Naval Aerospace Medical Research Laboratory, Pensacola, Florida $\$ 2512$
}

\begin{abstract}
A motorized chair (with precise servo controls) accelerated the observer in a clockwise (CW) or counterclockwise (CCW) direction at rates that ranged in logarithmic progression from 0.02 to $6.00 \mathrm{deg} / \mathrm{sec}^{2}$. The target, a narrow collimated line of light, was contained within a goggle device worn by the observer and therefore fixed in relative position to him. The illusion, appearing as rightward or leftward movement of the visual target in the direction of acceleration, was determined by a double staircase procedure among 300 normal and 4 labyrinthine-defective observers. None of the latter perceived the illusion. The majority of normal observers revealed no substantial directional difference (CW vs. CCW threshold). Threshold frequency distributions ranged in rate (deg/ $\mathrm{sec}^{2}$ ) from 0.020 to 0.950 ; the threshold of response in more than half the normal observers was less than 0.10 , in over three-fourths was less than 0.20 , in over $90 \%$ less than 0.30 , and $100 \%$ less than 1.00 .
\end{abstract}

The oculogyral illusion may be perceived by a person passively exposed to angular acceleration as apparent motion (in the direction of turn) of visual objects that are fixed relative to him (Graybiel \& Hupp, 1946). The illusion has its genesis in the semicircular canals, and a knowledge of cupuloendolymph mechanisms, the role of adaptation effects, and the influence of secondary etiological factors are all essential for predicting its behavior under different stimulus conditions (Clark, 1967; Clark \& Stewart, 1968; Doty, 1969; Graybiel et al., 1948). Studies have shown that its perception under ideal test conditions yields lower threshold values than other canal response indicators: the manifestation of nystagmus and the sensation and aftersensation of rotation (Clark, 1967; Clark \& Stewart, 1969; Dockstader, 1971; Gray, Note 1; Van Dishoeck, Spoor, \& Nijhoff, 1954). Indeed, the thresholds of the illusion are so low that their measurement is limited by the precision of the rotating device. A highly sophisticated servo-controlled device, the rotating litter chair (RLC), was developed expressly for determining with this indicator any changes in cupular thresholds of response that might occur during the prolonged weightless Skylab missions (Miller \& Graybiel, 1973). The purpose of this report is to measure thresholds of perception of the illusion with this new device in a large sample of normal male observers and in four deaf persons with severe bilateral labyrinthine defects.

This study was supported by Contract T-81633, Biomedical Research Oftice, and Contract T-5904B, Office of Life Sciences, National Aeronautics and Space Administration, Johnson Space Center, Houston, Texas. Opinions or conclusions contained in this report are those of the authors and do not necessarily reflect the views or endorsement of the Navy Department.

\section{METHOD}

\section{Subjects}

Three hundred normal healthy men, ranging in age from 17 to 49 years. served as test observers; most (261) of these observers were less than 26 years of age. This group comprised 203 pilots or pilot trainees. 44 enlisted personnel, and 53 civilians. Each was accepted as a subject after demonstrating normal otolith and semicircular canal function, as indicated, respectively, by ocular counterrolling (Miller. 1962, 1970) and caloric response (McLeod \& Meek, Note 2). In addition, four deaf individuals with severe bilateral labyrinthine defects. as defined in Table 1 , served in determining nonlabyrinthine influences upon the perception of rotation.

\section{Apparatus}

Rotating litter chair. The RLC is a relatively lightweight $(\approx 145 \mathrm{lb})$ motor-driven rotational chair device that is described elsewhere in detail (Miller \& Graybiel, 1973). A servo-controlled de brush-type motor is programmed to rotate automatically a seated observer at any one of 24 velocity vs. constant time $(90 \mathrm{sec}$ ) protiles (Figure 1) within extremely narrow limits of precision. The 24 which ranged from \pm 0.0007 (Step 1) to \pm 0.0084 (Step 24) $\mathrm{deg} / \mathrm{sec}$ extended trapezoidal-shaped profiles yielded in progressive logarithmic steps a range of constant accelerations from $0.02 \mathrm{deg} / \mathrm{sec}^{2}$ (Step 1) to $3.00 \mathrm{deg} / \mathrm{sec}^{2}$ (Step 23); two log units of acceleration separated Steps 23 and $24\left(6.00 \mathrm{deg} / \mathrm{sec}^{2}\right)$. The man-supporting superstructure and motor of the RLC are directly coupled to eliminate gear slack and perceptible vibration and therefore meet the physiological requirement of eliminating small performance errors that are normally with in the sensitivity range of the delicate vestibular organs.

Vestibular test goggle. The vestibular test goggle (VTG), described in detail elsewhere (Miller \& Graybiel, 1972), is a self-contained device worn over the observer's eyes (Figure 2). The collimated line-of-light target, the only thing visible to the observer, is selt-illuminated by a radioactive source (tritium gas, $100 \mathrm{mCi}$, AEC license No. 09-06979-03) contained in the goggle. Two knurled knobs permit the target to be rotated $360 \mathrm{deg}$ about its center and moved vertically, from a straight-ahead position, $\pm 20 \mathrm{deg}$ about the center of rotation of the viewing right eye; the left eye is occluded by being covered with a portion of the goggle. The device is held on the face by its attachment to a biteboard assembly, which, in turn. is sceured by an adjustable support connected to the RLC. The distance between the ocular and occlusal planes is adjusted so that 
Table 1

Clinical Findings in Four Deaf Observers With Bilateral Labyrinthine Defects

\begin{tabular}{|c|c|c|c|c|c|c|c|c|c|}
\hline \multirow[b]{2}{*}{ Observers } & \multirow[b]{2}{*}{ Age } & \multicolumn{2}{|c|}{ Deafness } & \multicolumn{2}{|c|}{ Hearing (dB) } & \multicolumn{2}{|c|}{ Caloric Response* } & \multirow{2}{*}{$\begin{array}{c}\text { Date of } \\
\text { Clinical } \\
\text { Tests }\end{array}$} & \multirow{2}{*}{$\begin{array}{c}\text { Counter- } \\
\text { rolling } \\
\text { Index } \dagger\end{array}$} \\
\hline & & Etiology & $\begin{array}{c}\text { Age of } \\
\text { Onset }\end{array}$ & $\mathbf{R}$ & $\mathbf{L}$ & $\mathbf{R}$ & $\mathbf{L}$ & & \\
\hline $\begin{array}{l}\text { G.R. } \\
\text { G.U. } \\
\text { M.Y. } \\
\text { P.E. }\end{array}$ & $\begin{array}{l}48 \\
22 \\
26 \\
33\end{array}$ & $\begin{array}{l}\text { Mastoiditis } \\
\text { Meningitis } \\
\text { Meningitis } \\
\text { Meningitis }\end{array}$ & $\begin{array}{l}12 \\
41 / 2 \\
8 \\
12\end{array}$ & $\begin{array}{l}\text { Nil } \\
>145 \\
\text { None } \\
\text { None }\end{array}$ & $\begin{array}{l}160 \\
>145 \\
\text { None } \\
\text { None }\end{array}$ & $\begin{array}{l}\text { Negligible } \\
\text { Negligible } \\
\text { None } \\
\text { Negligible }\end{array}$ & $\begin{array}{l}\text { Negligible } \\
\text { Negligible } \\
\text { None } \\
\text { Negligible }\end{array}$ & $\begin{array}{l}1967 \\
1967 \\
1967 \\
1967\end{array}$ & $\begin{array}{l}60 \\
89 \\
99 \\
77\end{array}$ \\
\hline
\end{tabular}

* Negligible or no observable nystagmus when tympanum irrigated with water at a temperature of $11^{\circ} \mathrm{C}$ or less.

fCalculated as one-half the sum of the eye roll measured in minutes of arc at the 50-deg rightward and leftward tilt positions.

the obsener's visual axis in its primary position is essentially in the "horizontal" plane containing the optic axis of the target system. The target was found to be compietely visible to all observers having a wide range of interpupillary distances; so no means of lateral adjustment was incorporated in the goggle.

\section{Procedure}

The oculogvral illusion was demonstrated at the time of the biteboard fitting by having the observer observe the apparent movement of the test-goggle target during gentle side-to-side movements.

The observer was then secured in a seated position within the RLC. and his biteboard and the VTG were affixed to the support mechanism of the chair. He engaged the biteboard with his teeth and donned the VTG by tilting his head forward $20 \mathrm{deg}$. The target viewed by his right eye was adjusted so that it appeared vertical and straight ahead. The purpose of the fixed head tilt was to place the "plane" of the lateral canals closer to the plane of rotation.

A sound source for signaling the normal observer was situated directly over his head. which eliminated it as a cue to the chair's rotational direction: the labyrinthine-defective observer was signaled by lightly tapping the top of his head. The rotational chair was located in a test cubicle, which permitted this area to be darkened and thereby removed any possible influence of any small openings between the goggle's padd ing and the face. During testing, auditory directional cues were effectively removed by having the normal observer wear earphones. All observers used hand-held. color-coded lights to signal. when requested, the direction of apparent movement of the target. After one of the 24 acceleration rates was selected on the basis of the predetermined test schedule and observer performance. the program start switch of the RLC was pressed. After $2 \mathrm{sec}$ of constant positive acceleration, the observer was signaled to open his eyes, after $5 \mathrm{sec}$ accumulative time. he was

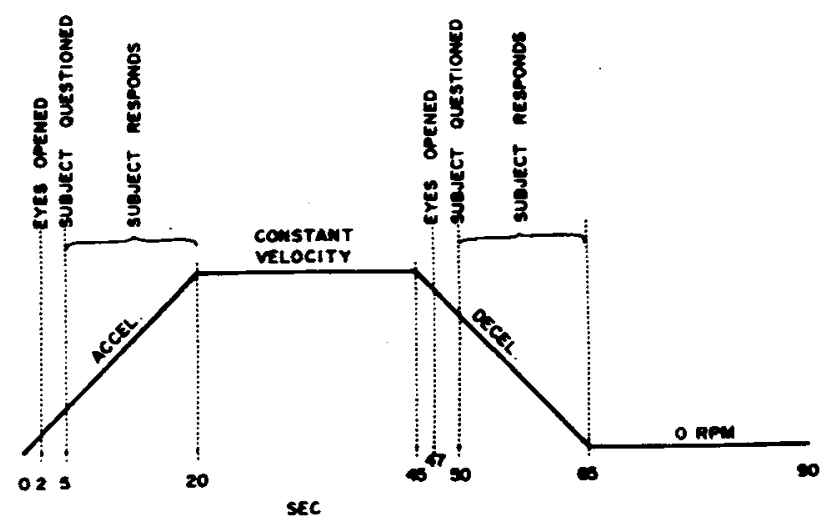

Figure 1. Diagram of a test-cycle profile indicating chair rotational mode and experimental activity as a function of time. signaled again to judge whether the target appeared to move rightward or lefiuard. or to remain stationary. If the observer did not respond after $15 \mathrm{sec}$ accumulative time, a third signal was given. If no response was received within $20 \mathrm{sec}$ accumulative time. the end of the constant acceleration period and the beginning of the 25-sec constant velocity phase. it was assumed and recorded that no movement was perceived. The observer was instructed to close his eves immediately after each response.

The down ramp of the profile required the observer. as in positive acceleration. to open his eves at $2 \mathrm{sec}$ and to respond between the 5th and 20 th second after deceleration had begun. After reaching $0 \mathrm{rpn}$, the RLC remained stationary for at least $25 \mathrm{sec}$. In some cases. the next profile was not initiated for up to several minutes when: (1) the total test time exceeded $30 \mathrm{~min} .(2)$ when the observer requested additional rest time. or (3) for operational reasons. e.g.. wiping the goggle lens to remove a moisture film that occasionally was found to accumulate. The direction of rotation among the profiles was varied at random according to a predetermined schedule.

In selecting an intertrial period between velocity ramps of at least $25 \mathrm{sec}$, an attempt was made to reduce the test time without introducing significant poststimulus response effects. Although the analysis of such effects was not part of this study. it was found in the development of the test method that these particular test conditions vielded on the average no essential differences between up-ramp and down-ramp responses of the same direction when the interval between profiles was several times that between ramps. This assumption is more acceptable tor this study when it is considered that only relatively low levels of acceleration $\left(<1.00 \mathrm{deg}_{\text {/ }} \mathrm{sec}^{2}\right)$ were employed for the normal subjects.

Our early experimental probes had indicated that a brief period of feedback training at an acceleration level well above response threshold was necessary to establish that the observer understood the task and could readily observe the illusory movement. The observer was also fully apprised that apparent movement of the target in this situation did not also require its apparent displacement. particularly at or near his response threshold level. During training conducted at Acceleration Step 12. or higher if necessars. the observer was informed of his results and coached until he could consistently identify the direction of the oculogyral illusion. During the actual test. the observer was not provided this teedback.

Mechanically, the stimulus to the cupuloendolymph system and therefore its response with clockwise (CW) acceleration is equivalent to those for counterclockwise (CCW) deceleration, as in the reterse sense are the pair of complementary directions of acceleration and deceleration. For convenience. each stimulus pair is henceforth identified only by its associated direction of acceleration.

A response threshold for each of the two directions of accekration was defined as the lowest acceletation at which the observer could correctly identify the expected direction of apparent movement in three out of four or in four out of six trials. When a difference in perception of the illusion for the two directions of acceleration was manitested at any step. the threshold for the 


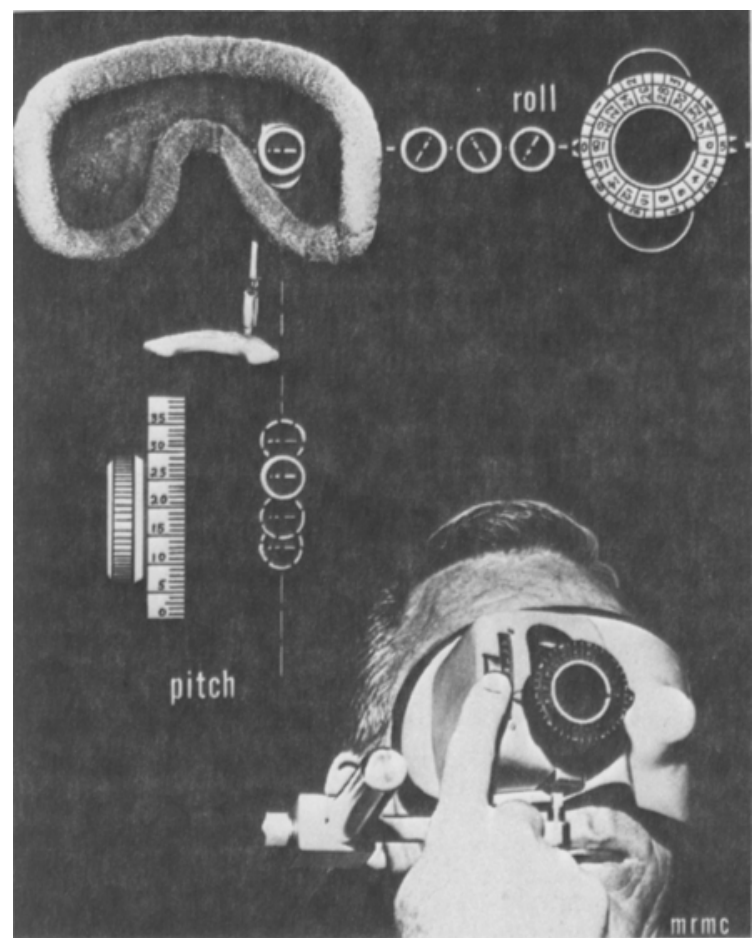

Figure 2. Diagram of the vestibular test goggle (VTG).

direction of better performance was pursued first. Testing generally followed a double-staircase method (Cornsweet, 1962). Initially, an attempt was made to bracket the threshold within six log steps. If. for example, at least one response associated with the first test prolile (usually Step 12) was correct, testing proceeded to Step 6. If a response of like direetion was correct at Step 6, further testing continued in the range of accelerations between Steps 1 and 6; if not. the test range fell between Steps 6 and 12. On the other hand, if both responses at the initial step were incorrect, the two staircases proceeded from, usually, Step 15 and the initial acceleration step. In all cases, testing followed the pattern of alternately lowering the higher step and raising the lower one of the indicated range. Securing the testing if it became apparent that the threshold was in a dilferent range, the 6 or less log step bracket was shifted in the appropriate dircction. Ascending-descending staircases permitted an ever decreasing range of testing until the threshold was captured between two steps of acceleration. This permitted a relatively rapid gross estimation of a threshold, with the greater portion of the test time spent in "fine tuning" of the threshold. Typically, repeated trials were alternately made at the final two steps until the threshold criteria were established. On occasion, the threshold fell between the two steps and in this case the threshold was assigned to the higher acceleration step. There were four subjects who exceeded the threshold criterion even at the lowest acceleration level (Step 1) provided by the device prior to assigning a threshold. Except in this instance, it was always established that the next lower step failed to meet the threshold criterion. If the thresholds for $\mathrm{CW}$ and $\mathrm{CCW}$ acceleration were different, testing continued in similar fashion using. if possible. the data already obtained until the higher threshold was determined. The test was completed in more than hall the observers within $30 \mathrm{~min}$. and in most within $40 \mathrm{~min}$. although occasionally about $1 \mathrm{~h}$ was required. In no case was the observer tested longer than $30 \mathrm{~min}$ without one or more rest periods prior to completion of the test; each rest period of about 5 min was instituted with the observer remaining in the RLC but with his head removed from the goggle and biteboard support.

The oculogyral illusion threshold of each normal observer was measured by this procedure on two different occasions, separated by at least $24 \mathrm{~h}$. in order to determine test-retest reliability.

\section{RESULTS AND DISCUSSION}

The large number of trials and long test periods often covering many days or weeks that are typical in measurements of a response threshold were avoided in this study without apparent undue compromise in sensitivity or reliability by using 24 logarithmic step levels of accelerative stimuli. On a linear basis, this schedule introduced ever-increasing increments of acceleration among the progressive test steps with the result, desirable from a practical point of view, that

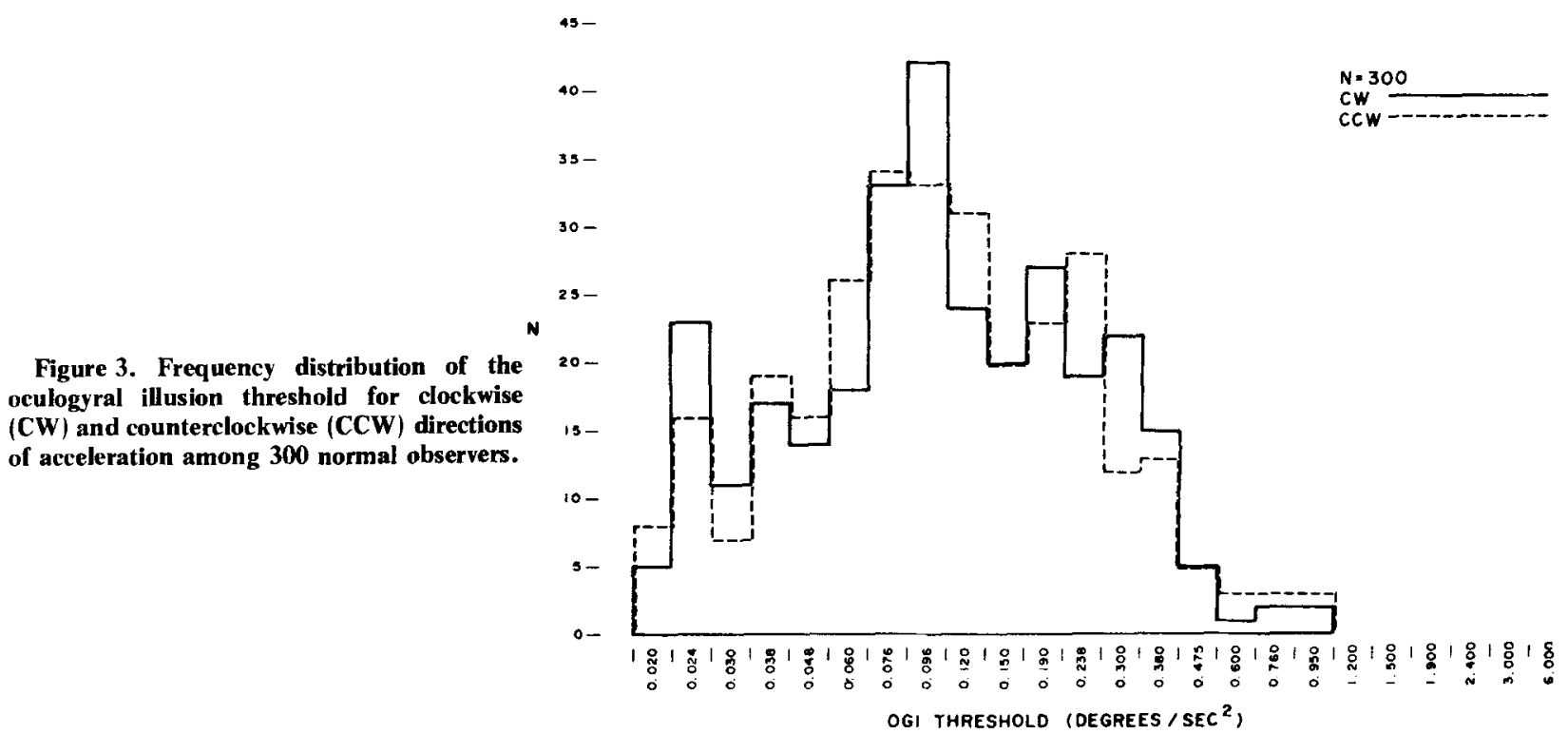


differentiability among individuals decreases as an indirect function of threshold level.

Directional difference, i.e., a difference in threshold for $\mathrm{CW}$ and $\mathrm{CCW}$ acceleration, was not manifested in $35 \%$, was less than $0.1 \mathrm{deg} / \mathrm{sec}^{2}$ in $84 \%$, and less than $0.2 \mathrm{deg} / \mathrm{sec}^{2}$ in $94 \%$ of the normal observers; the remaining observers revealed a difference that ranged from 0.2 to $0.7 \mathrm{deg} / \mathrm{sec}^{2}$. Furthermore, a moderately high correlation $(p=.72)$ was found to exist between data obtained with $\mathrm{CW}$ and $\mathrm{CCW}$ acceleration. A substantial directional (CW vs. CCW) difference in the oculogyral illusion (OGI) threshold response would therefore not be the expected result in a normal individual. A follow-up investigation of the small number of observers who demonstrated a relatively large directional difference was not conducted, but a study of unilaterally labyrinthectomized individuals gave some evidence that an acute unilateral vestibular disturbance may cause a difference (Miller et al., Note 3).

The individual thresholds for $\mathrm{CW}$ and $\mathrm{CCW}$ acceleration were averaged to obtain a single measure of test-retest reliability, which proved to be moderately high $(p=.70)$. This level of reliability and the brief test period required make the method feasible as a clinical-type test of semicircular canal function. The large sample of normative data offers a substantial basis for comparing the OGI thresholds of response of individuals with possible vestibular disfunction.

Frequency distributions of the oculogyral illusion threshold values among all the normal observers for $\mathrm{CW}$ and $\mathrm{CCW}$ acceleration are presented in Figure 3. The distributions were similar for the two directions of angular acceleration and ranged in terms of rate (degrees per second per second) from 0.020 to 0.950 , means of $0.146(\mathrm{CW})$ and $0.152(\mathrm{CCW})$, a median of $0.096(\mathrm{CW}, \mathrm{CCW})$, and modes of $0.096(\mathrm{CW})$ and $0.076(\mathrm{CCW})$. The distributions on a linear scale are skewed right. More than half the individual thresholds fell below $0.10 \mathrm{deg} / \mathrm{sec}^{2}$; over three-fourths were less than $0.20 \mathrm{deg} / \mathrm{sec}^{2}$; over $90 \%$ less than $0.30 \mathrm{deg} / \mathrm{sec}^{2}$; and $100 \%$ less than $1.00 \mathrm{deg} / \mathrm{sec}^{2}$. These findings compare well with those of Clark and Stewart (1968) who found that the OGI thresholds of their 32 observers ranged from $0.04 \mathrm{deg} / \mathrm{sec}^{2}$ (close to the lower limit of their device) up to $0.28 \mathrm{deg} / \mathrm{sec}^{2}$, and confirm their conclusion that normal healthy adult men have semicircular canals that are highly sensitive to accelerative stimulation.

All labyrinthine-defective observers failed repeated- ly to perceive the oculogyral illusion at the highest acceleration step $\left(6.00 \mathrm{deg} / \mathrm{sec}^{2}\right)$ offered by the RLC test device, giving further evidence that the basic underlying mechanism for this illusion is the copuloendolymph system.

\section{REFERENCES}

CLARK, B. Thresholds for the perception of angular acceleration in man. Aerospace Medicine, 1967, 38, 443-450.

Clark. B.. \& Stewart, J. D. Comparison of sensitivity for the perception of bodily rotation and the oculogyral illusion. Perception \& Psychophysics, 1968, 3, 254-256.

Clark, B., \& Stewart, J. D. Effects of angular acceleration on man: Thresholds for the perception of rotation and the oculogyral illusion. Aerospace Medicine, 1969, 40, 952-956.

CornsweEt, T. N. The staircase-method in psychophysics. American Journal of Psychology, 1962, 75. 485-491.

Dockstader, S. L. Comparison of cupulometric and psychophysical thresholds for perception of rotation and the oculogyral illusion. Perception \& Psychophysics, 1971, 9, 299-302.

Doty, R. L. Effect of duration of stimulus presentation on the angular acceleration threshold. Journal of Experimental Psychology, 1969, 80, 317-321.

Graybiel, A., \& Hupp, D. I. The oculogyral illusion: A form of apparent motion which may be observed following stimulation of the semicircular canals. Journal of Aviation Medicine, 1946, 17, 3-27.

Graybiel, A., Kerr, W. A., \& Bartley, S. H. Stimulus thresholds of the semicircular canals as a function of angular acceleration. American Joumal of Psychology. 1948, 61, 21-36.

Miller, E. F., II. Counterrolling of the human eyes produced by head tilt with respect to gravity. Acta Otolaryngologica, $1962,54,479-501$.

Milier, E. F.. II. Evaluation of otolith function by means of ocular counterrolling measurements. In J. Stahle (Ed.). Vestibular function on earth and in space. Oxford: Pergamon Press, 1970.

Miller. E. F.. II, \& Graybiel, A. Experiment M-131. Human vestibular function. Aerospace Medicine, 1973, 44. 593-608.

Van Dishoeck, H. A. E., Spoor, A., \& Nijhoff, P. The opto-gyral illusion and its relation to the nystagmus of the eyes. Acta Otolaryngologica, 1954, 44, 597-607.

\section{REFERENCE NOTES}

1. Gray, R. F. Relationships between oculogyral illusions and nystagmus. NADC-MA-5609, U.S. Naval A ir Development Center, Johnsville, Pa., 1956.

2. McLeod, M. E.. \& Meek. J. C. A threshold caloric test: Results in normal subjects. NSAM-834, Naval School of Aviation Medicine, Pensacola, Fla., 1962.

3. Miller, E. F., 11, Pulec, J. L., Wilcox, J. G., \& Graybiel, A. Specitic acute losses of vestibular function in man following unilateral section of one or all components of the eighth cranial nerve. NAMRL-1156. Naval Aerospace Medical Research Laboratory, Pensacola, Fla., 1972.

(Received for publication April 1, 1974; revision received December $2,1974$. ) 